\title{
Pemanfaatan Sensor pada Smartphone Android untuk Rekomendasi Pembibitan Tanaman
}

\author{
Sony Heri Maulana ${ }^{1}$, Eko Budi Setiawan ${ }^{2}$ \\ Program Studi Teknik Informatika, Universitas Komputer Indonesia, Jl. Dipatiukur 112 Bandung \\ sonyherimaulana@gmail.com \\ eko@email.unikom.ac.id
}

Diterima 14 November 2018

Disetujui 21 Desember 2018

\begin{abstract}
Ornamental plants are plants that can meet psychological needs, improve the environment, and have the value of satisfaction as a hobby. Functionally, ornamental plants can help renew oxygen in the air, helping to reduce gas pollutants and noise. Then it takes an android application that can provide recommendations for ornamental plants using mobile sensor technology. The sensors used a humidity sensor, temperature sensor, and an ambient light sensor. This research using openweather map where the three sensors detect the level of humidity, temperature, and light intensity in the user environment. The application will recommend plants that are suitable for the environment, for openweather as a sensor replacement if not supported by the sensor.
\end{abstract}

Index Terms - rekomendasi tanaman, humidity sensor, temperature sensor, ambient light sensor

\section{PENDAhUluAN}

Tanaman hias memiliki banyak keanekaragaman dari bentuk, warna dan aroma. Semuanya dapat kita gunakan untuk mempercantik rumah sesuai dengan yang diharapkan. Tanaman hias adalah tanaman yang dapat memenuhi kebutuhan psikologis, meningkatkan lingkungan serta memiliki nilai kepuasan sebagai hobi [1] [2]. Tanaman hias yang sering kita sebut dengan bunga ini juga memberi manfaat terhadap lingkungan seperti mengurangi pencemaran udara dan polutan lainnya [3]. Secara fungsional, tanaman hias juga dapat membantu memperbarui oksigen di udara, membantu mengurangi polutan gas dan tingkat kebisingan.

Salah satu karakteristik tanaman hias dapat dibedakan berdasarkan fisik dan tempat hidup tanaman hias tersebut, dengan identifikasi tanaman baik secara fisik maupun hortikultura, maka proses pemilihan, pengelolaan dan penempatan tanaman hias menjadi lebih tepat dan sesuai, serta fungsi tanaman menjadi lebih optimal [4] [5].

Perbedaan ketinggian suatu tempat berdampak pada iklim yang berbeda, daerah dataran rendah memiliki suhu yang tinggi dan kelembaban udara yang rendah maka tanaman yang membutuhkan suhu tinggi dan kelembaban rendah tumbuh baik di dataran rendah, sedangkan pada daerah yang lebih tinggi, yaitu dataran medium suhunya lebih rendah dan kelembaban udaranya lebih tinggi, maka tanaman yang membutuhkan suhu sedang dan kelembaban udara sedang akan tumbuh baik di dataran medium, namun kurangnya pengetahuan masyarakat tentang tanaman hias kurang optimal [6].

Tanaman hias tidak hanya bisa kita tanam di dalam ruangan, tanaman hias juga bisa ditanam di area luar ruangan. Sehingga tidak hanya tampilan dalamnya saja yang menjadi cantik, tetapi tampilan luar ruangan pun menjadi cantik dengan adanya tanaman hias [7] [8]. Cara menanam tanaman hias tidak bisa dilakukan dengan sembarangan, harus memiliki pedoman dan pengetahuan tentang tanaman yang ditanam dan yang paling utama adalah memperhatikan media tanamannya yaitu seperti tanah yang cocok digunakan untuk tanaman yang dipilih, pupuk yang digunakan, kadar air untuk menyiramnya, serta peramalan cuaca sekaligus merawatnya [9] [10].

Oleh karena itu dibutuhkan suatu aplikasi yang menggunakan perangkat mobile berbasis android yang dapat membantu masyarakat dalam cara menanam pembibitan tanaman hias. Penelitian ini memanfaatkan sensor pada smartphone android untuk memberikan rekomendasi kepada pengguna dalam hal pembibitan tanaman hias.

\section{TINJAUAN PUSTAKA}

\section{A. Tanaman Hias}

Tanaman hias dengan segala keindahannya dapat menimbulkan efek imajinasi yang luas dan menghidupkan kembali semangat diri. Tanaman hias berupa bunga didefinisikan sebagai tumbuhan yang mempunyai bunga berpesona cantik dengan satu atau banyak warna. Tanaman hias bunga dapat menambah keindahan suatu ruangan atau lingkungan di sekitarnya serta membuatnya terlihat lebih asri [4]. Ada banyak jenis tanaman hias bunga yang bisa ditanam di dalam ataupun di luar rumah. Masyarakan banyak yang 
menanam tanaman hias yang bertujuan untuk mempercantik rumahnya.

\section{B. Syarat Tumbuh Tanaman Hias}

Syarat tumbuh beberapa tanaman hias dapat dilihat pada tabel 1 [11].

Tabel 1 Syarat Tumbuh Tanaman Hias

\begin{tabular}{|c|c|c|c|}
\hline No & $\begin{array}{c}\text { Tanaman } \\
\text { Hias }\end{array}$ & $\begin{array}{l}\text { Nama } \\
\text { Latin }\end{array}$ & Syarat Tumbuh \\
\hline 1 & Sri Rejeki & $\begin{array}{l}\text { Aglaone } \\
\text { ma } \\
\text { crispum }\end{array}$ & $\begin{array}{l}\text { 1. Ketinggian yang cocok } \\
\text { sekitar } 300-400 \mathrm{~m} \text { dpl } \\
\text { 2. Suhu, tumbuh ideal pada } \\
\text { kondisi suhu di daerah } \\
\text { dataran rendah. } \\
\text { 3. Kelembaban } 50-75 \% \text {. } \\
\text { 4. Cahaya, tidak } \\
\text { membutuhkan terlalu } \\
\text { banyak matahari. berada di } \\
\text { dataran sedang, gunakan } \\
\text { shading net } 20 \%-25 \% \text {. }\end{array}$ \\
\hline 2 & $\begin{array}{c}\text { Begonia } \\
\text { atau Daun } \\
\text { Antik }\end{array}$ & $\begin{array}{l}\text { Begonia } \\
\text { rex }\end{array}$ & $\begin{array}{l}\text { 1. Intensitas cahaya berkisar } \\
\text { antara } 2000-2500 \mathrm{fc} \text {. } \\
\text { 2. Suhu, antara } 15-30{ }^{\circ} \mathrm{C} \text {. } \\
\text { 3. Kebutuhan air, begonia } \\
\text { rentan jika kondisi media } \\
\text { berlebih air. } \\
\text { 4. Kelembapan udara yaitu } \\
\text { diatas 50\% diusahakan } \\
\text { jangan terlalu tinggi. }\end{array}$ \\
\hline 3 & $\begin{array}{l}\text { Bromelia } \\
\text { Pink Grass }\end{array}$ & $\begin{array}{l}\text { Bromelia } \\
\text { sp. }\end{array}$ & $\begin{array}{l}\text { 1. Cahaya merata dan harus } \\
\text { dinaungi dengan net } \\
\text { pelindung dengan kisaran } \\
60 \%-75 \% \text {. } \\
\text { 2. Intensitas cahaya, butuh } \\
\text { naungan } 65 \%-75 \% \text {. } \\
\text { 3. Suhu } 16^{\circ} \mathrm{C}-26^{\circ} \mathrm{C} \text { iklim } \\
\text { tropis maupun sub tropis. } \\
\text { 4. Kelembapan dari } 50 \%-60 \\
\% \text {. }\end{array}$ \\
\hline 4 & $\begin{array}{l}\text { Bunga } \\
\text { Krisan }\end{array}$ & $\begin{array}{l}\text { Chrysant } \\
\text { hemum } \\
\text { morifoliu } \\
m\end{array}$ & $\begin{array}{l}\text { 1. Suhu udara } 20^{\circ} \mathrm{C}-26^{\circ} \mathrm{C} \\
\text { 2. Kelembapan, } \\
\text { membutuhkan kelembaban } \\
\text { tinggi untuk awal } \\
\text { pembentukan akar bibit, } \\
\text { setek memerlukan 90-95\%. } \\
\text { 3. Cahaya matahari, } \\
\text { membutuhkan penyinaran } \\
\text { yang lama } \\
\text { 4. Ketinggian tempat 700- } \\
\text { 1200 m dpl }\end{array}$ \\
\hline 6 & $\begin{array}{l}\text { Bunga } \\
\text { Kertas }\end{array}$ & $\begin{array}{l}\text { Bougainv } \\
\text { illea } \\
\text { berberidi } \\
\text { folia }\end{array}$ & $\begin{array}{l}\text { 1. Suhu, } 10^{\circ} \mathrm{C}-20^{\circ} \mathrm{C} \text { (suhu } \\
\text { malam) dan siang hari } \\
19^{\circ} \mathrm{C}-29^{\circ} \mathrm{C} \\
\text { 2. Kelembapan antara } 50-80 \\
\% \\
\text { 3. Cahaya, } \\
\text { membutuhkan penyinaran } \\
\text { penuh }\end{array}$ \\
\hline
\end{tabular}

\section{Sensor}

Sensor adalah alat yang dapat digunakan untuk mengukur, menganalisa, memantau suatu kondisi dan kemudian merespon terhadap perubahan di sekitarnya. Alat ini dapat ditemukan pada perangkat modern seperti smartphone dengan sistem operasi android, sebagai ponsel pintar yang memiliki sepaket teknologi canggih [12]. Tiga sensor yang dipergunakan dalam penelitian ini yaitu ambient light sensor, temperatur dan humidity sensor.

\section{Ambient Light Sensor}

Ambient light sensor adalah alat yang digunakan untuk mengatur kecerahan layar secara otomatis berdasarkan cahaya sekitar. Selain itu sensor ini juga berfungsi sebagai pengukur atau penghitung intensitas cahaya yang ada pada sekitar kita, sehingga sensor akan mendeteksi dan menampilkan intensitas cahaya yang masuk.

\section{Temperatur Sensor}

Temperatur sensor adalah alat yang digunakan untuk mengukur suhu yang ada pada lingkungan sekitarnya. Suhu udara adalah suatu keadaan panas atau dinginnya udara disuatu tempat pada waktu tertentu, yang dipengaruhi oleh banyak atau sedikitnya panas matahari yang diterima oleh bumi.

\section{Humidity Sensor}

Humidity sensor adalah alat yang digunakan untuk mengukur kelembaban udara yang ada pada lingkungan sekitarnya. Sensor ini cocok untuk mengukur tingkat kelembaban sekitar sehingga kesesuaian suatu tanaman hias untuk tumbuh dapat diketahui.

\section{Global Positioning System (GPS)}

Global positioning system (GPS) adalah suatu sistem navigasi atau penentuan posisi berbasis satelit. Sistem ini didesain untuk memberikan posisi dan informasi mengenahi waktu, secara menerus di seluruh dunia tanpa tergantung waktu dan cuaca. Penentuan gps digambarkan dengan menggunakan nilai koordinat $\mathrm{X}$ dan $\mathrm{Y}$ atau garis bujur dan garis lintang (longitude atau latitude) [13] [14].

\section{E. OpenWeatherMap}

Openweather map adalah layanan online yang menyediakan data cuaca termasuk data cuaca terkini, perkiraan dan data historis untuk pengembang layanan web dan aplikasi seluler. Untuk sumber data, openweather map menggunakan layanan dari siaran meteorologi, stasiun cuaca bandara, stasiun radar, dan data dari stasiun cuaca resmi lainnya. Semua data diproses oleh openweather map untuk memberikan data perkiraan cuaca dan peta cuaca yang akurat secara online, seperti awan atau curah hujan. Ide ini terinspirasi oleh openstreet map dan wikipedia yang membuat informasi gratis dan tersedia untuk semua orang. Perbedaannya, openweather map ini digunakan untuk menampilkan peta cuaca. Script dari openweather maps dapat dilihat di gambar 1.

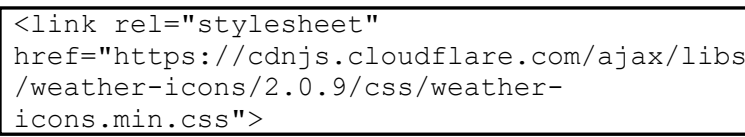

Gambar 1 Script Key API Openweather Map

Contoh script untuk mengambil data API openweather map, menampilkan nama kota, suhu, kelembapan, cahaya, cuaca dan perediksi cuaca 


\section{ISSN 2085-4552}

beberapa hari ke depan. Gambar 2 merupakan tampilan hasil koneksi ke API openweather map.

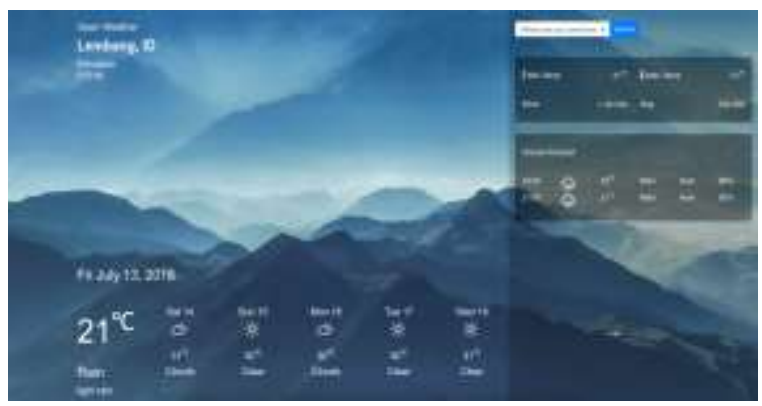

Gambar 2 Tampilan Hasil Koneksi ke API Open Weather Map

\section{Metodologi Penelitian}

Metode yang digunakan dalam penelitian ini menggunakan alur atau skema penelitian yang dapat dilihat pada gambar 3 .

\section{HASIL DAN PEMBAHASAN}

\section{A. Analisis dan Perancangan Sistem}

Analisis dan perancangan sistem sistem bertujuan untuk mengidentifikasikan permasalahanpermasalahan yang terdapat pada sistem, serta menentukan kebutuhan-kebutuhan dari sistem yang dibangun. Analisis tersebut meliputi analisis masalah, analisis arsitektur sistem, analisis kebutuhan fungsional dan analisis data [15].

\section{A.1 Analisis masalah}

a. Petugas pertanaman mengalami kesulitan untuk mengetahui tanaman hias apa yang cocok dengan kondisi lingkungan tanaman tersebut.

b. Ketika para petugas menanam bibit tanaman hias kesulitan untuk merawatnya karena tanaman tersebut tidak cocok untuk di kondisi lingkungan yang menanami bibit tanaman hias tersebut, maski tanaman tersebut bagus, indah untuk di tanam di lingkungan itu.

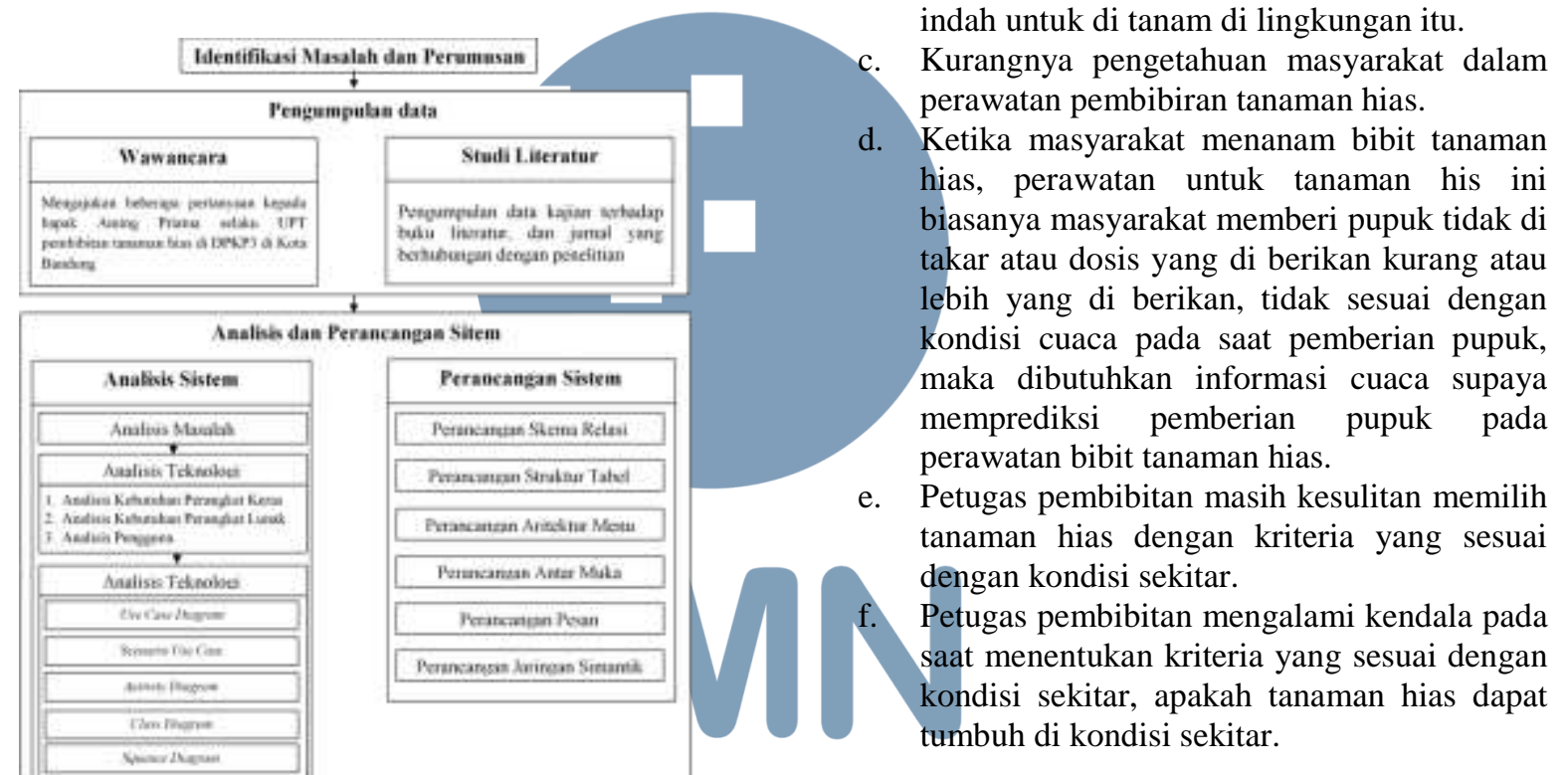

\section{A.2 Analisis Arsitektur Sistem}

Analisis arsitektur sistem bertujuan untuk mengidentifikasi arsitektur yang dibangun. Gambar 4 berikut merupakan arsitektur sistem dari aplikasi rekomendasi pencarian tanaman hias.

Gambar 3 Alur Penelitian

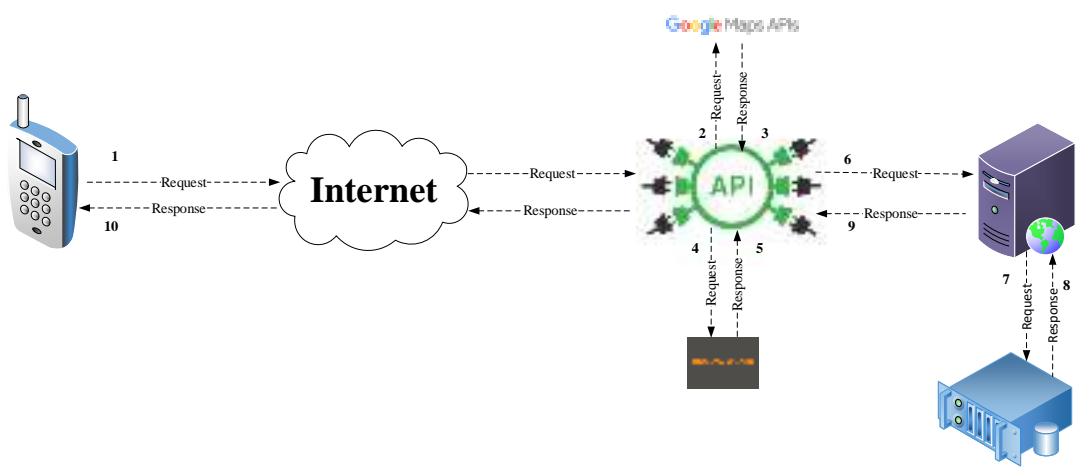

Gambar 4 Arsitektur Sistem 
Berikut penjelasan dari gambar 3 arsitektur sistem :

1. Perangkat mobile pengguna melakukan request data web server melalui API melalui jaringan internet.

2. API melakukan request data Api Google Maps

3. API Google Maps mengirimkan data dan mengirimkan kembali untuk melanjutkan ke API Openweather maps

4. API Melakukan request data API Openweather

5. API Openweather menerima permintaan dan meberikan data

6. Web server menerima request data dari API dan menentukan jenis request yang di terima oleh API.

7. Web server menerima permintaan data dan web server mengambil data yang ada di database.
8. Web server menerima kiriman data dan web server menyimpan data pada database.

9. Setelah web server menerima data yang diminta data tersebut dikembalikan dalam bentuk JSON untuk diproses perangkat mobile pengguna.

10. Kemudian mengirim response ke pengguna sesuai permintaannya.

A.3 Use Case Aplikasi Mobile Android

Sebuah use case merepresentasikan interaksi antara aktor dengan sistem. Use case sangat menentukan karakteristik sistem yang sedang dibuat. Sebuah aktor adalah sebuah entitas manusia atau mesin yang berinteraksi dengan sistem untuk melakukan pekerjaan-pekerjaan tertentu [16]. Adapun use case diagram dari aplikasi yang dibangun dapat dilihat pada gambar 5 .

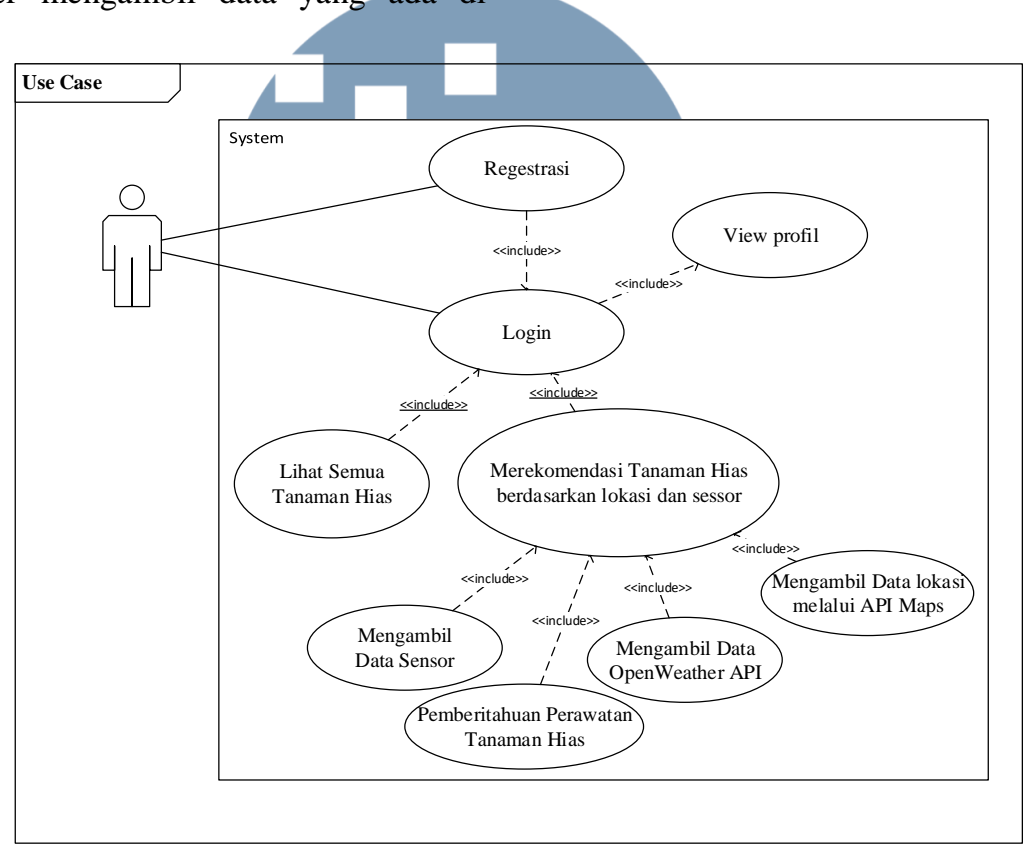

Gambar 5 Use Case Diagram

\section{A.4 Analisis cara kerja sensor}

Pada pembangunan aplikasi ini menggunakan tiga sensor yaitu ambient light, temperatur dan humidity sensor. Ketiga sensor tersebut menghasilkan suatu data berupa rekomendasi tanaman yang cocok untuk lingkungan sekitarnya, dimana data yang didapatkan dari sensor tersebut berupa angka namun pengguna hanya mendapatkan rekomendasi nama tanamannya.

Penjelasan mengenai sensor yang digunakan sebagai berikut.

1. Ambient Light Sensor

Ambinet light sensor pada aplikasi mobile ini digunakan untuk mengukur intensitas cahaya, dimana keakuratan hasil dipengaruhi oleh faktor kecerahan layar seperti layar yang lebih terang membantu untuk pendeteksiannya, kedekatan dan sudut permukaan yang memantulkan cahaya di atas permukaan sensor menghasilkan hasil yang baik, namun jika kurangnya permukaan yang memantulkan cahaya membuat proses pendeteksian mendapatkan hasil yang kurang maksimal. Intensitas cahaya yang diukur adalah unit lux. Data keluaran berkisar antara 0 (gelap) sampai puluhan ribu lux. Untuk frekuensi pembacaan dari sensor relatif tinggi, memungkinkan pembacaan pada 100-200 milidetik.

Cara kerja pada sensor ini adalah dengan cara hardware pendeteksi cahaya yang berada pada smartphone mengirimkan informasi data intensitas cahaya yang didapatkan, cara kerja ini meliputi. 
a) Posisikan smartphone ditempat yang intensitas cahayanya lebih terang dengan layar berada diposisi atas, pastikan LED sensor cahaya yang berada pada smartphone tersebut tidak tertutupi.

b) Smatrphone mendeteksi secara langsung berapa intensitas cahaya yang didapatkan.

2. Temperature dan humidity

Temperature dan humidity adalah sensor yang mendeteksi suhu dan kelembaban suatu lingkungan atau ruangan, satuan yang digunakan pada sensor ini adalah ${ }^{\circ} \mathrm{C}$ untuk suhu dan \% untuk kelembaban, dimana kedua komponen ini saling berhubungan, jika suhu semakin tinggi maka kelembaban semakin rendah begitupun sebaliknya.

Sensor humidity adalah sensor yang disediakan oleh smartphone dengan kualifikasi smartphone hightend, sehingga tidak semua smartphone memiliki sensor tersebut.

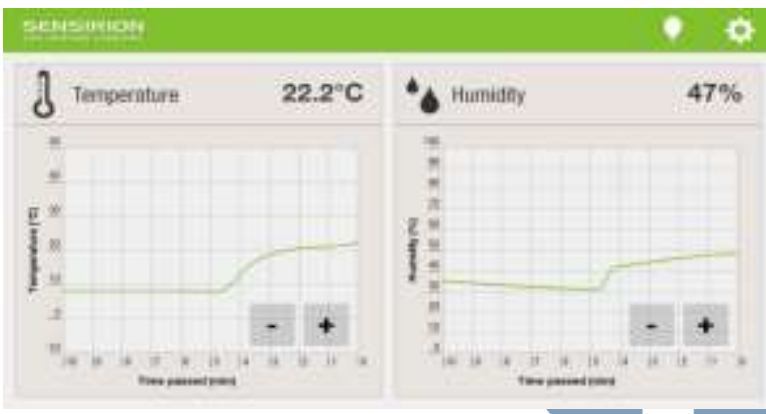

Gambar 6 Perbandingan Temperatur dan Humidity

\section{A.5 Studi Kasus Sensor Pada Aplikasi}

Contoh untuk mendapatkan data sensor yang diinginkan dapat dilihat pada studi kasus berikut ini. Misalkan pada sebuah lingkungan didapatkan data dari sensor. Data tersebut dapat dilihat pada tabel 2 dan tabel 3 sebagai berikut.

Tabel 2 Data Sensor

\begin{tabular}{|l|l|}
\hline \multicolumn{1}{|c|}{ Sensor } & \multicolumn{1}{c|}{ Angka } \\
\hline Humidity & $75.5 \%$ \\
\hline Temperature & $30.5^{\circ} \mathrm{C}$ \\
\hline Ambient Light & 30 \\
\hline
\end{tabular}

Tabel 3 Data Bunga

\begin{tabular}{|l|c|c|c|c|c|c|}
\hline \multirow{2}{*}{$\begin{array}{c}\text { Nama } \\
\text { Tanaman }\end{array}$} & \multicolumn{2}{|c|}{$\begin{array}{c}\text { Humidity } \\
(\%)\end{array}$} & \multicolumn{2}{c|}{$\begin{array}{c}\text { Temperature } \\
\left({ }^{\mathbf{O}} \mathbf{C}\right)\end{array}$} & \multicolumn{2}{c|}{$\begin{array}{c}\text { Ambient } \\
\text { Light (Lx) }\end{array}$} \\
\cline { 2 - 7 } & Min & Max & Min & Max & Min & Max \\
\hline Krisan & 69.33 & 79.75 & 28 & 32.50 & 14.530 & 42.771 \\
\hline Ararea & 60 & 80 & 24.999 & 30.89 & 21.575 & 31.28 \\
\hline Begonia & 50 & 50 & 15 & 30 & 20.00 & 25.00 \\
\hline
\end{tabular}

Dari data tabel 2 diatas telah didapatkan data dari sensor, setelah data dari sensor didapatkan maka aplikasi mencari data pada database untuk mencari data humidity, temperatur dan ambient light yang sesuai seperti pada tabel 3 pencocokan data tersebut dilakukan dengan membuat query pada tabel bunga dan pencarian bunga, agar data yang dicari cocok dengan data yang didapatkan pada sensor [17]. Misalkan kita memiliki satu tabel berupa tabel data tanaman pencarian bunga, dimana isi dari tabel pencarian bunga seperti pada tabel 4 .

Tabel 4 Data Tanaman Pencarian Bunga

\begin{tabular}{|c|c|c|}
\hline $\begin{array}{c}\text { Nama } \\
\text { Tanaman }\end{array}$ & $\begin{array}{c}\text { Jenis } \\
\text { Tanaman }\end{array}$ & Lokasi \\
\hline Krisan & Tanaman hias & $\begin{array}{c}6^{\circ} 56^{\prime} 48.8^{\prime \prime} \mathrm{S} \\
107^{\circ} 43^{\prime} 05.0 \text { '” }\end{array}$ \\
\hline Ararea & Tanaman Hias & $\begin{array}{c}6^{\circ} 56^{\prime} 48.8^{\prime} \mathrm{S} \\
107^{\circ} 43^{\prime} 05.0 \text { ' } \mathrm{E}\end{array}$ \\
\hline
\end{tabular}

Dari ketiga tabel tersebut satu query untuk mendapatkan data bunga yang cocok adalah sebagai berikut.

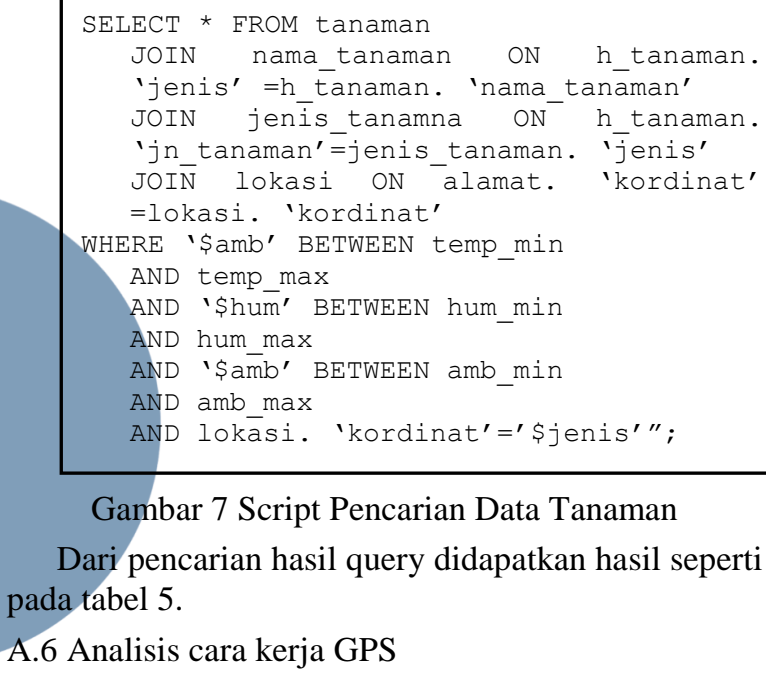

Gambar 7 Script Pencarian Data Tanaman

Dari pencarian hasil query didapatkan hasil seperti

A.6 Analisis cara kerja GPS pada tabel 5

Dalam smartphone sebenarnya bukan GPS, melainkan-bagian yang ada dalam GPS yaitu bagian penerima atau untuk lebih memudahkannya disebut dengan sistem navigasi [18]. Cara kerja yang dilakukan adalah sebagai berikut

Setelah GPS pada smartphone aktif selanjutnya kemudian mengirimkan permintaan lokasi pada satelit.

2. Dengan mendapatkan laporan dari satelit tersebut, sistem navigasi di dalam smartphone dapat memperhitungkan dimana posisinya berada pada permukaan bumi.

3. Sistem navigasi terebut mengolah data yang diterima dan kemudian ditampilkan dalam bentuk yang dimengerti oleh manusia seperti dalam bentuk koordinat bumi atau dengan berupa media gambar seperti halaman peta.

Cara kerja GPS selengkapnya dapat dilihat pada gambar 8 . 
ISSN 2085-4552

Tabel 5 Data Hasil Query

\begin{tabular}{|c|c|c|c|c|c|c|c|c|}
\hline \multirow{2}{*}{$\begin{array}{c}\text { Nama } \\
\text { Tanaman }\end{array}$} & \multirow{2}{*}{$\begin{array}{c}\text { Jenis } \\
\text { Tanaman }\end{array}$} & \multirow{2}{*}{ Koordinat } & \multicolumn{2}{|c|}{ Humidity (\%) } & \multicolumn{2}{|c|}{ Temperature $\left({ }^{\circ} \mathrm{C}\right)$} & \multicolumn{2}{|c|}{ Ambient Light (Lx) } \\
\hline & & & Min & Max & Min & Max & Min & Max \\
\hline Krisan & $\begin{array}{c}\text { Tanaman } \\
\text { Hias } \\
\end{array}$ & $\begin{array}{c}6^{\circ} 56^{\prime} 48.8^{\prime \prime} \mathrm{S} \\
107^{\circ} 43^{\prime} 05.0^{\prime \prime} \mathrm{E}\end{array}$ & 69.33 & 79.75 & 28 & 32.50 & 14.530 & 42.771 \\
\hline Ararea & $\begin{array}{c}\text { Tanaman } \\
\text { HIas }\end{array}$ & $\begin{array}{c}6^{\circ} 56^{\prime} 48.8^{\prime \prime} \mathrm{S} \\
107^{\circ} 43^{\prime} 05.0^{\prime \prime} \mathrm{E}\end{array}$ & 60 & 80 & 24.999 & 30.89 & 21.575 & 31.28 \\
\hline
\end{tabular}

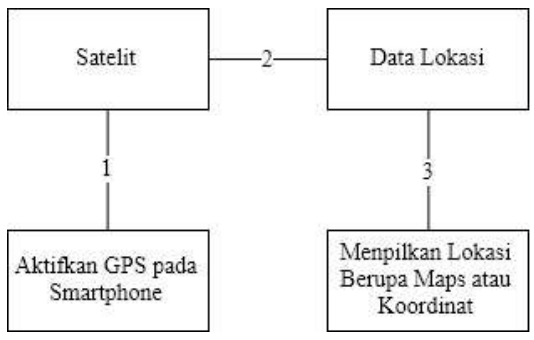

Gambar 8 Cara Kerja GPS secara umum

\section{A.7 Analisis Cara Kerja OpenWeatherMap}

Untuk mengakses ke API Openweather map adalah menggunakan script seperti pada gambar 9 .

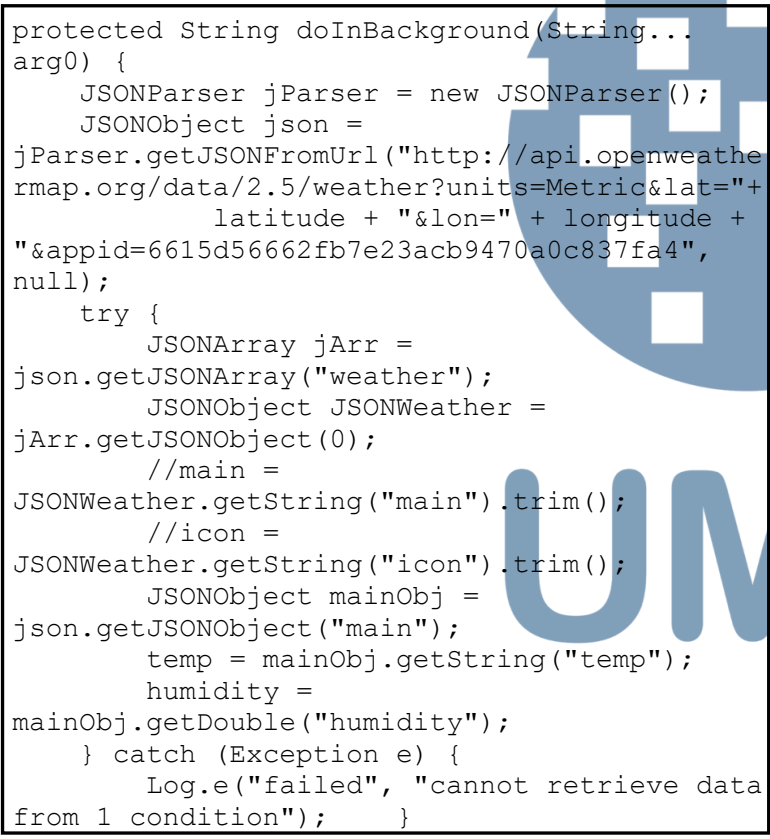

Gambar 9 Script Openweather Map

Script tersebut bisa menampilkan cuaca, suhu, kelembapan, cahaya, seperti gambar 10 dan 11.

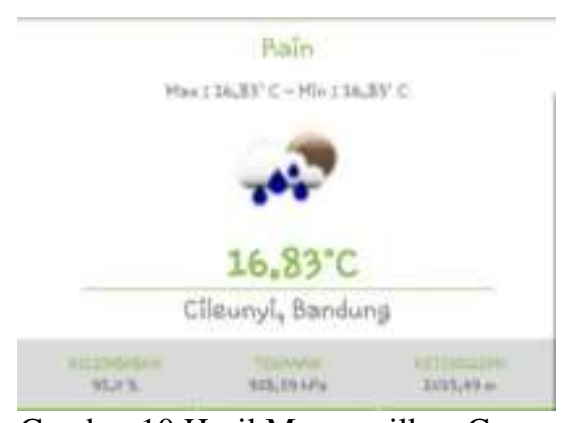

Gambar 10 Hasil Menampilkan Cuaca

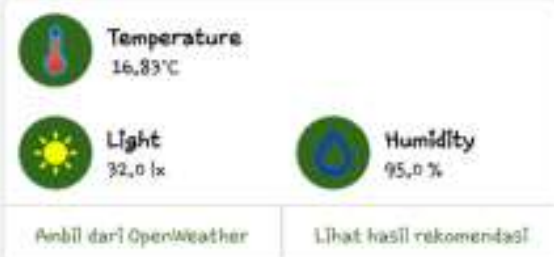

Gambar 11 Hasil Menampilkan Suhu, Kelembapan, Cahaya

\section{B. Implementasi Sistem}

Implementasi merupakan tahapan penciptaan perangkat lunak dan juga tahapan kelanjutan dari perancangan aplikasi. Tahap ini merupakan tahap dimana aplikasi siap untuk dioperasikan. Tahap ini terdiri dari penjelasan mengenai lingkungan perangkat lunak, implementasi antarmuka serta implementasi pengujian aplikasi [19].

\section{B.1 Implementasi Perangkat Lunak}

Adapun spesifikasi perangkat lunak yang digunakan untuk menjalankan aplikasi pemanfaatan sensor pada smartphone android untuk rekomendasi pembibitan tanaman dapat dilihat pada tabel 6 .

Tabel 6 Spesifikasi Perangkat Lunak

\begin{tabular}{|c|l|}
\hline No & \multicolumn{1}{|c|}{ Jenis perangkat Keras } \\
\hline 1. & Sistem Operasional Microsoft Windows 7, 64-bit \\
\hline 2. & Browser Google Crome \\
\hline 3. & IDE Android Studio 2.3.3 \\
\hline 4. & Andorid SDK API 4.0 (lever15) \\
\hline 5. & Text Editor Sublime Text 3 \\
\hline
\end{tabular}

\section{B.2 Implementasi Antar Muka}

Implementasi antarmuka dilakukan terhadap setiap tampilan aplikasi yang dibangun dan pengkodeannya dalam bentuk file aplikasi. Tabel 7 berikut ini adalah implementasi antar muka pada platform mobile.

Tabel 7 Implementasi Antar Muka

\begin{tabular}{|c|l|c|}
\hline \multicolumn{3}{|c|}{ Implementasi Antar Muka Pada Platform Mobile } \\
\hline Menu & \multicolumn{1}{|c|}{ Deskripsi } & Nama File \\
\hline \multirow{2}{*}{ Registrasi } & $\begin{array}{l}\text { Merupakan Halaman } \\
\text { Registrasi untuk pengguna } \\
\text { ketika ingin masuk dan } \\
\text { mengakses aplikasi }\end{array}$ & $\begin{array}{c}\text { RegristasiAct } \\
\text { ivity.java }\end{array}$ \\
\hline Login & $\begin{array}{l}\text { Merupakan Halaman login } \\
\text { untuk pengguna ketika ingin } \\
\text { menggunakan aplikasi }\end{array}$ & $\begin{array}{c}\text { LoginActivit } \\
\text { y.java }\end{array}$ \\
\hline Profil & $\begin{array}{l}\text { Menampilkan halaman untuk } \\
\text { melihat detail akun }\end{array}$ & $\begin{array}{c}\text { ProfilActivit } \\
\text { y.java }\end{array}$ \\
\hline Tanaman & $\begin{array}{l}\text { Menampilkan list semua } \\
\text { tanaman }\end{array}$ & $\begin{array}{c}\text { TanamanActi } \\
\text { vity.java }\end{array}$ \\
\hline
\end{tabular}


ISSN 2085-4552

\begin{tabular}{|l|l|c|}
\hline \multicolumn{3}{|c|}{ Implementasi Antar Muka Pada Platform Mobile } \\
\hline \multicolumn{1}{|c|}{ Menu } & \multicolumn{1}{|c|}{ Deskripsi } & Nama File \\
\hline $\begin{array}{l}\text { Rerekomenda } \\
\text { si Tanaman } \\
\text { Hias }\end{array}$ & $\begin{array}{l}\text { Menampilkan halaman untuk } \\
\text { merekomendasikan tanaman } \\
\text { hias dengan mendeteksi } \\
\text { melalui sensor }\end{array}$ & $\begin{array}{l}\text { Rekomendasi } \\
\text { Activity.java }\end{array}$ \\
\hline $\begin{array}{l}\text { Perkiraan } \\
\text { cuaca }\end{array}$ & $\begin{array}{l}\text { Menampilkan kondisi cuaca } \\
\text { sekitar }\end{array}$ & $\begin{array}{c}\text { MainActivity } \\
\text { java }\end{array}$ \\
\hline $\begin{array}{l}\text { Tentang } \\
\text { Aplikasi }\end{array}$ & $\begin{array}{l}\text { Menampilkan halaman } \\
\text { diskripsi mengenai fungsi } \\
\text { aplikasi }\end{array}$ & $\begin{array}{l}\text { tentangActivi } \\
\text { ty.java }\end{array}$ \\
\hline
\end{tabular}

\section{Pengujian Sistem}

Pengujian merupakan bagian yang penting dalam siklus pengembangan perangkat lunak. Pengujian terhadap aplikasi itu sendiri bertujuan agar berjalan dengan baik tanpa mengalami kesalahan sehingga memungkinkan untuk dilakukannya pengembangan sistem yang lebih lanjut. Pengujian sistem dalam penelitian ini terdiri dari pengujian alpha dan pengujian beta.

Pengujian sistem yang dilakukan terbagi menjadi dua tahapan. Tahap pertama yaitu pengujian alpha dan tahap kedua dilakukan penelitian terhadap responden atau pengguna sistem dengan melakukan pengumpulan data menggunakan angket kuesioner. Metode pengujian yang digunakan dalam pengujian betha adalah metode pertanyaan dengan skala likert.

\section{C.1. Pengujian Alpha}

Pengujian alpha dilakukan dengan menggunakan metode black-box yang berfokus pada persyaratan fungsional perangkat lunak. Tujuan dari metode blackbox ini adalah untuk menemukan kesalahan fungsi pada aplikasi. Apabila dari data masukan yang diberikan proses menghasilkan keluaran yang sesuai dengan kebutuhan fungsionalnya, maka aplikasi yang telah dibuat telah berjalan dengan baik. Tetapi jika keluaran yang dihasilkan tidak sesuai dengan kebutuhanfungsional, maka terdapat kesalahan aplikasi. Hasil pengujian alpha dapat dilihat pada tabel 8.

Tabel 8 Pengujian Fungsional

\begin{tabular}{|c|c|c|}
\hline $\begin{array}{c}\text { Implementasi } \\
\text { Antar Muka }\end{array}$ & \multicolumn{1}{|c|}{ Detail Pengujian } & $\begin{array}{c}\text { Hasil } \\
\text { Pengujian }\end{array}$ \\
\hline & & \\
& $\begin{array}{ll}\text { Menampilkan } \\
\text { halaman login }\end{array}$ & {$[\sqrt{ }]$ Sukses } \\
& $\begin{array}{l}\text { Pengguna } \\
\text { memasukan } \\
\text { username dan } \\
\text { password }\end{array}$ & $\begin{array}{c}\text { Sesuai } \\
\text { dengan } \\
\text { hasil yang } \\
\text { diharapkan }\end{array}$ \\
\hline & & \\
\hline & & \\
\hline
\end{tabular}

\begin{tabular}{|c|c|c|}
\hline $\begin{array}{c}\text { Implementasi } \\
\text { Antar Muka }\end{array}$ & Detail Pengujian & $\begin{array}{c}\text { Hasil } \\
\text { Pengujian }\end{array}$ \\
\hline 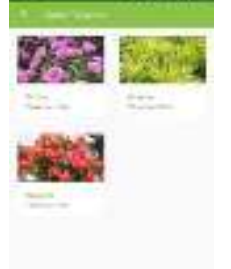 & $\begin{array}{ll}\text { 1. } & \text { Menampilkan list } \\
\text { tanaman } \\
\text { 2. } \\
\text { 3. } \\
\text { Memilih tanaman } \\
\text { Menampilkan } \\
\text { detail tanaman }\end{array}$ & $\begin{array}{c}{[\sqrt{ }] \text { Sukses }} \\
\text { Sesuai } \\
\text { dengan } \\
\text { hasil yang } \\
\text { diharapkan }\end{array}$ \\
\hline 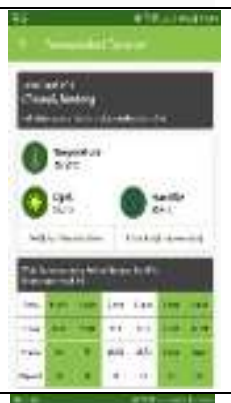 & 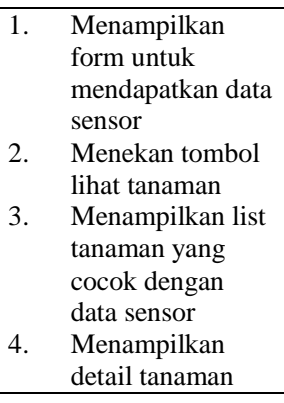 & $\begin{array}{c}{[\sqrt{ } \text { ] Sukses }} \\
\text { Sesuai } \\
\text { dengan } \\
\text { hasil yang } \\
\text { diharapkan }\end{array}$ \\
\hline$\frac{0}{-\frac{0}{0} \frac{\theta}{0}}$ & $\begin{array}{ll}\text { 1. } & \text { Meminta ke api } \\
\text { openweather } \\
\text { 2. } \\
\text { Mendapatkan } \\
\text { data cuaca }\end{array}$ & $\begin{array}{c}{[\sqrt{ }] \text { Sukses }} \\
\text { Sesuai } \\
\text { dengan } \\
\text { hasil yang } \\
\text { diharapkan }\end{array}$ \\
\hline
\end{tabular}

\section{C.2. Hasil Pengujian Beta}

Adapun pernyataan pada kuesioner yang dintanyakan pada tanggal 7 Agustus 2018 kepada 8 orang petugas Dinas Perumahan dan Kawasan Permukiman, Pertanahan dan Pertamanan (DPKP3) sebagai pengguna dari sistem. Hasil pengujiannya dapat dilihat pada tabel 9.

\section{Tabel 9 Hasil Pengujian Beta}

Pertanyaan Pertaman : Aplikasi ini memberikan rekomendas dalam pencarian tanaman hias yang cocok dengan lingkungan Petugas

\begin{tabular}{|c|c|c|c|c|}
\hline SS & $\mathbf{S}$ & $\mathbf{R}$ & TS & STS \\
\hline 6 & 1 & 1 & 0 & 0 \\
\hline \multicolumn{5}{|c|}{ Rata-rata $=(37 /(8 \times 5)) \times 100=92,5 \%$} \\
\hline \multicolumn{5}{|c|}{$\begin{array}{l}\text { Pertanyaan Kedua : Aplikasi ini memberikan rekomendasi } \\
\text { dalam pencarian tanaman hias yang sesuai dengan kriteria yang } \\
\text { petugas inginkan }\end{array}$} \\
\hline SS & $\mathbf{S}$ & $\mathbf{R}$ & TS & STS \\
\hline 4 & 3 & 1 & 0 & 0 \\
\hline \multicolumn{5}{|c|}{ Rata-rata $=(35 /(8 \times 5)) \times 100=87,5 \%$} \\
\hline \multicolumn{5}{|c|}{ Pertamyaam ketiga : Tampilan aplikasi ini cukup menarik } \\
\hline SS & $\mathbf{S}$ & $\mathbf{R}$ & TS & STS \\
\hline 2 & 6 & 0 & 0 & 0 \\
\hline \multicolumn{5}{|c|}{ Rata-rata $=(34 /(8 \times 5)) \times 100=85 \%$} \\
\hline \multicolumn{5}{|c|}{$\begin{array}{l}\text { Pertanyaan keempat : Aplikasi ini menggunakan bahasa yang } \\
\text { mudah dipahami }\end{array}$} \\
\hline SS & $\mathbf{S}$ & $\mathbf{R}$ & TS & STS \\
\hline 4 & 2 & 2 & 0 & 0 \\
\hline \multicolumn{5}{|c|}{ Rata-rata $=(34 /(8 \times 5)) \times 100=85 \%$} \\
\hline \multicolumn{5}{|c|}{ Pertanyaan kelima : Aplikasi ini mudah dipahami dan digunakan } \\
\hline SS & $\mathbf{S}$ & $\mathbf{R}$ & TS & STS \\
\hline 5 & 2 & 1 & 0 & 0 \\
\hline
\end{tabular}




\begin{tabular}{|c|c|c|c|c|}
\hline \multicolumn{5}{|c|}{$\begin{array}{l}\text { Pertanyaan Pertaman : Aplikasi ini memberikan rekomendasi } \\
\text { dalam pencarian tanaman hias yang cocok dengan lingkungan } \\
\text { Petugas }\end{array}$} \\
\hline SS & $\mathbf{S}$ & $\mathbf{R}$ & TS & STS \\
\hline
\end{tabular}

Dari hasil perhitungan pengujian pada tabel 9, didapatkan bahwa kesimpulan hasil pengujian yaitu menurut responden bahwa aplikasi ini sudah dapat membantu dalam pembibitan tanaman. Hasil tersebut dibuktikan dengan hasil rata-rata akhir nilai dari kuesioner yaitu 88\%. Hasil penghitungan juga dituangkan dalam bentuk interval pada gambar 12 .

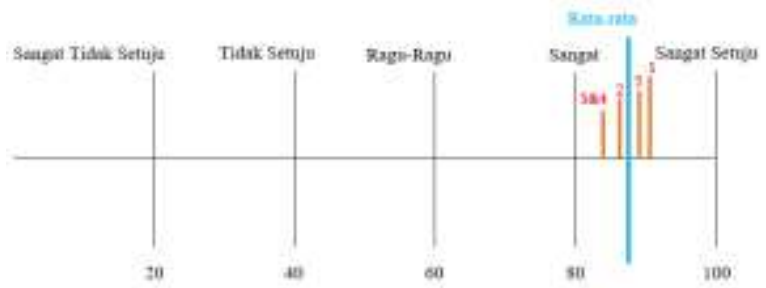

Gambar 12 Interval Hasil Pengujian Beta

Berdasarkan hasil dari proses penelitian yang dilakukan, mulai dari analisis, perancangan, implementasi, serta pengujian, maka didapat kesimpulan sebagai berikut:

1. Aplikasi ini sangat membantu pengguna dalam mendapatkan rekomendasi pencarian tanaman hias yang sesuai dengan lingkungan tempat sekitar dan kriteria bibit tanaman hias yang sesuai.

2. Aplikasi ini juga dapat membantu untuk pemeliharan tanaman hias.

Pengujian yang dilakukan pada penelitian ini baru membahas pengujian fungsionalitas saja. Pengujian terkait sensor, akurasi dan metode algoritma yang digunakan akan dilakukan pada penelitian selanjutnya.

\section{SIMPULAN}

Kesimpulan dari penelitian ini yaitu aplikasi yang dibuat telah berhasil membantu dalam merekomendasikan pencarian tanaman hias berdasarkan lingkungan dan kriteria yang diinginkan oleh pengguna.

\section{DAFTAR PUSTAKA}

[1] E. Choirun Nisa, A. Fikriarini M, MT dan D. Abdussakir, M.Pd, "Integrasi Tema Pragmatik Dengan Nilai Keislaman Pada Perancangan Arboretum Tanaman Hias Di Kota Batu," Arboretum Tanaman Hias, vol. 1, p. 2, 2015.

[2] D. Syahid, Junadi dan D. Nursantika, "Sistem Klasifikasi Jenis Tanaman Hias Daun Philodendron Menggunakan Metode K-Nearest Neighboor (KKN) Berdasarkan Nilai Hue, Saturation, Value (HSV(," vol. 1, no. 2527-9165, pp. 1-4, 2016.

[3] A. Sulistyorini, Biologi 1, Jakarta: Pusat Perbukuan Departemen Pendidikan Nasional, 2009.
[4] Her Angga Febrianta, Endang Slistyaningsih, and Siti Nurul Rofiqo Irwan, "Identifikasi Karakteristik Dan Fungsi Tanaman Hias Untuk Tanaman Rumah Di Dataran Medium Dan Dataran Rendah," Taman Hias, vol. 1, no. 26, pp. 23-43, 2012.

[5] B. Rahadiyan Adita C dan N. Ratni J. A. R, "Tingkat Kemampuan Penyerapan Tanaman Hias Dalam Menurunkan Polutan Karbon Monoksida," Tingkat Kemampuan Penyerapan Tanaman, vol. 4, no. 1, pp. 1-7, 2013.

[6] H. Anggara Febriarta, E. Sulistyaningsuh dan S. Nurul Rofiqo Irwan, "Identifikasi Karakteristik dan Fungsi Tanaman Hias Untuk Tanaman Rumah Di Dataran Medium dan Dataran Rendah," Karakteristik Fisik, vol. 1, no. 1, pp. 1-12, 2012.

[7] Y. Nasihin, "Teknik Peningkatan Produksi Benih Krisan Dengan Aplikasi Pupuk Kabing," Buletin Teknik Pertanian, vol. 17, no. 1, pp. 22-25, 2012.

[8] L. Widiastuti, Tohari dan E. Sulistyaningsih, "Pengaruh Intensitas Cahaya dan Kadar Daminosida Terhadap Mikro dan Pertumbuhan Tanaman Krisan Dalam Pot," Ilmu Pertanian, vol. 11, pp. 35-42, 2004.

[9] W. Handayati, "Pengembangan Pemulihan Mutasi Tanaman Hias di Indonesia," Balai Pengkajian Teknologi Pertanian Jawa Timur, vol. 1, no. 2, pp. 1-14, 2013.

[10] A. F. Her, S. Endang dan N. R. I. Siti, "Identifikasi Karakteristik dan Fungsi Tanaman Hias untuk Taman Rumah di Dataran Medium dan Dataran Rendah," Tanaman Hias, vol. 1 , no. 2 , p. $8,2012$.

[11] Istianingrum, Putri; , Damanhuri; Soetopo, Lita; "Pengaruh Generasi Benih Terhadap Pertumbuhan Dan Pembungaan Krisan (Chrysanthemun) Varietas Rhino," Produksi Tanaman, vol. 1, no. 3, pp. 1-8, 2013.

[12] A. Nur Sari dan D. Sunaryono, "Perancangan dan Pembangunan Perangkat Lunak Photo Uploader pada Facebook dengan Fitur Geotagging," Jurnal Teknik Pomits, vol. 1 , no. 1 , p. $2,2012$.

[13] A. Nurwanto, J. Rizki, P. Johannes dan P. Iis, "Rancang Bangun Aplikasi Sistem Observasi Berbasis Android dan Web," Aplikasi Sistem, vol. 2, no. 3, pp. 1-10, 2016.

[14] A. Juansyah, "Pembangunan Aplikasi Child Tracker Berbasis Assited-Global Positioning System (A-GPS)Dengan Platform Android," Jurnal Ilmiah Komputer dan Informatika (KOMPUTA), vol. 1, p. 4, 2015.

[15] R. A. S. dan M. Shalahuddin, Rekayasa Perangkat Lunak Tersetruktur dan Berorientasi Objek, Bandung: Informatika, 2013.

[16] Jogiyanto, Pengenakan Komputer, Yogyakarta: Andi Yogyakarta, 2011.

[17] W. Qousim, "Variabilitas Generim Karakter Morfologi Tanaman Krisan," Program Pascasarjana, vol. 1, no. 3, p. 60, 1999.

[18] Berbudi Rachman and Herny Februariyanti, "Aplikasi Location Based Service (LBS) Pencarian Lokasi Taxi Pada Android Di Kota Semarang," Location Based Service, vol. 5, no. 4, pp. 1-8, Maret 2013.

[19] S. Mulyono dan EB, Setiawan, "Analisis dan Pengujian Web Service Restful Partner API Terintegrasi dengan EPP API untuk Regestrasi ccTLD Indoensia," Pengujian Web Service, vol. 2, no. 4, pp. 1-8, 2017. 